\title{
Article
}

\section{Influence of Chronic Ocular Hypertension on Emmetropia: Refractive, Structural and Functional Study in Two Rat Models}

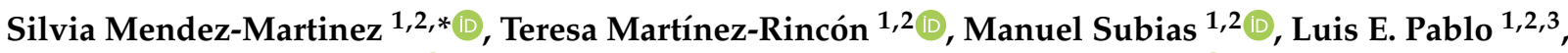 \\ David García-Herranz ${ }^{4,5,6} \oplus^{\circ}$, Julian García Feijoo ${ }^{3,7}$, Irene Bravo-Osuna ${ }^{3,4,5}$, Rocío Herrero-Vanrell ${ }^{3,4,5}$ (), \\ Elena Garcia-Martin ${ }^{1,2,3}$ a and María J. Rodrigo ${ }^{1,2,3}$
}

1 Department of Ophthalmology, Miguel Servet University Hospital, 50009 Zaragoza, Spain; teresamrincon@gmail.com (T.M.-R.); manusubias@gmail.com (M.S.); lpablo@unizar.es (L.E.P.); egmvivax@yahoo.com (E.G.-M.); mariajesusrodrigo@hotmail.es (M.J.R.)

2 Miguel Servet Ophthalmology Research Group (GIMSO), Aragon Health Research Institute (IIS Aragon), 50009 Zaragoza, Spain

3 National Ocular Pathology Network (OFTARED), Carlos III Health Institute, 28040 Madrid, Spain; jgarciafeijoo@hotmail.com (J.G.F.); ibravo@ucm.es (I.B.-O.); rociohv@farm.ucm.es (R.H.-V.)

4 Innovation, Therapy and Pharmaceutical Development in Ophthalmology (InnOftal) Research Group, UCM 920415 Department of Pharmaceutics and Food Technology, Faculty of Pharmacy, Complutense University of Madrid, 28040 Madrid, Spain; davgar07@ucm.es

check for updates

Citation: Mendez-Martinez, S.; Martínez-Rincón, T.; Subias, M.; Pablo, L.E.; García-Herranz, D.; Feijoo, J.G.; Bravo-Osuna, I.; Herrero-Vanrell, R.; Garcia-Martin, E.; Rodrigo, M.J. Influence of Chronic Ocular Hypertension on Emmetropia: Refractive, Structural and Functional Study in Two Rat Models. J. Clin. Med. 2021, 10, 3697. https:// doi.org/10.3390/jcm10163697

Academic Editor: Maria

Letizia Salvetat

Received: 19 July 2021

Accepted: 17 August 2021

Published: 20 August 2021

Publisher's Note: MDPI stays neutral with regard to jurisdictional claims in published maps and institutional affiliations.

Copyright: (C) 2021 by the authors Licensee MDPI, Basel, Switzerland. This article is an open access article distributed under the terms and conditions of the Creative Commons Attribution (CC BY) license (https:/ / creativecommons.org/licenses/by/ $4.0 /)$.
5 Health Research Institute, San Carlos Clinical Hospital (IdISSC), 28040 Madrid, Spain

6 University Institute for Industrial Pharmacy (IUFI), School of Pharmacy, Complutense University of Madrid, 28040 Madrid, Spain

7 Department of Ophthalmology, San Carlos Clinical Hospital (IdISSC), Complutense University of Madrid, 28040 Madrid, Spain

* Correspondence: oftalmosmm@gmail.com; Tel.: +34-9-7676-5558

Abstract: Chronic ocular hypertension (OHT) influences on refraction in youth and causes glaucoma in adulthood. However, the origin of the responsible mechanism is unclear. This study analyzes the effect of mild-moderate chronic OHT on refraction and neuroretina (structure and function) in young-adult Long-Evans rats using optical coherence tomography and electroretinography over 24 weeks. Data from 260 eyes were retrospectively analyzed in two cohorts: an ocular normotension (ONT) cohort ( $<20 \mathrm{mmHg}$ ) and an OHT cohort $(>20 \mathrm{mmHg})$, in which OHT was induced either by sclerosing the episcleral veins (ES group) or by injecting microspheres into the anterior chamber. A trend toward emmetropia was found in both cohorts over time, though it was more pronounced in the OHT cohort $(p<0.001)$, especially in the ES group $(p=0.001)$ and males. IOP and refraction were negatively correlated at week $24(p=0.010)$. The OHT cohort showed early thickening in outer retinal sectors $(p<0.050)$ and the retinal nerve fiber layer, which later thinned. Electroretinography demonstrated early supranormal amplitudes and faster latencies that later declined. Chronic OHT accelerates emmetropia in Long-Evans rat eyes towards slowly progressive myopia, with an initial increase in structure and function that reversed over time.

Keywords: glaucoma; intraocular pressure; refractive error; neuroretina; myopia

\section{Introduction}

An increase in intraocular pressure (IOP) is the main factor for developing primary open-angle glaucoma (POAG), which leads to chronic progressive optic neuropathy and is a leading cause of irreversible blindness worldwide [1]. An association between POAG and high myopia was found, as highly myopic patients experience increased risk and earlier onset [2] of this sight-threatening disease [3-6]. The prevalence of myopia and high myopia (spherical equivalent less than $-6.00 \mathrm{D}$ ) in the global population is currently $28.3 \%$, and this is expected to increase by 2050 [7]. Highly myopic eyes suffer from structural changes such as peripheral retinal atrophic areas, tilted nerve appearance, temporal crescent of 
the optic disc [8], vitreoretinal traction, retinoschisis, lamellar or complete macular hole, retinal pigment epithelium (RPE) alterations and myopic choroidal neovascularization, lacquer cracks and chorioretinal atrophy, decreased choroidal thickness, scleral thinning with irregular curvature and staphyloma [9], and decreased retinal nerve fiber layer (RNFL) thickness, among others [10]. All these structural differences in myopic eyes are probably related to biomechanical stretching resulting from the imbalance between IOP and the elastic properties of the sclera [11-14]. Several animal and human studies have claimed the baropathic nature of axial myopia [15]. Indeed, several topical ocular hypotensive drugs were used in animal $[16,17]$ and in human [18] studies to demonstrate the influence of IOP on axial length and refractive errors.

Unfortunately, POAG is difficult to diagnose in highly myopic eyes as the structural configuration of the optic nerve acts as a confounder variable in diagnostic tests such as spectral domain optical coherence tomography (SD-OCT), visual fields and electroretinography (ERG) [19-22]. Commercially available OCT devices still do not accurately measure RNFL thickness using automatic segmentation protocols in highly myopic eyes, exhibiting thinner average distributions in the superior, nasal, and inferior sectors, with greater temporal thickness, and a temporal shift in the superior and inferior peak locations [9].

To overcome the difficulties of structural diagnosis, OCT-based ganglion cell layer (GCL) analysis was proposed as a parameter for earlier detection of glaucomatous damage in myopic patients [23]. However, glaucoma is an aging-linked neurodegenerative pathology, so age could be a confounding factor in SD-OCT measurements. Indeed, animal studies showed contradictory results, with no definitive correlation between aging and thinning of the GCL [24-27] as detected in other neurodegenerative diseases [28], especially with the RNFL parameter [29-31]. Electrophysiological tests also showed functional impairment in patients affected by ocular hypertension, glaucoma, demyelinating optic neuropathies and Alzheimer's disease in both human [32] and animal studies [33,34], with a functional electrical deficit followed by structural tomographic thinning [35], even without visual dysfunction [34]. Hence, there is ample scope for studying the physiopathology of neurodegenerative diseases, aging, myopia and glaucoma.

The aim of this study is to analyze the impact of chronic ocular hypertension (OHT) on the refractive error, structure and function of the neuroretina in two different OHT-inducing animal models, comparing it with a control cohort presenting ocular normotension (ONT) over 24 weeks.

\section{Materials and Methods}

A retrospective study was conducted by collecting data from a proprietary database of animal glaucoma projects (PI17/01946, MAT2017-83858-C2-2). To investigate the impact of IOP on the eye, 260 rat eyes were classified as inclusion criteria into ONT (if IOP was $<20 \mathrm{mmHg}$ ) or OHT (if IOP was $>20 \mathrm{mmHg}$ ) cohorts.

\subsection{Animals}

Long-Evans rats ( $40 \%$ male, $60 \%$ female) were used for the study. All animals were four weeks old, their weights ranged from 50-100 g at the start of the study and were similar to that reported by the supplier (Janvier-labs, Le Genest-Saint-Isle, France) over the study. The animal study was carried out in the experimental surgery department of the Biomedical Research Center of Aragon (CIBA). The experiments were previously approved by the Ethics Committee for Animal Research (PI34/17) and were carried out in strict accordance with the Association for Research in Vision and Ophthalmology's Statement for the use of Animals.

The control ONT cohort included non-intervened eyes. The OHT cohort comprised the episcleral sclerosis (ES) group, in which OHT was induced by biweekly sclerosis of the episcleral veins with hypertonic $(1.8 \mathrm{M})$ solution as described [36]. The microspheres (MS) group, in which OHT was induced by injecting poly-lactic-acid-glycolic (PLGA) microspheres into the anterior chamber at baseline biweekly for the first month and then 
once monthly until week 20 as described [35,37]. All OHT injections were performed in the right eye under surgical conditions: controlled temperature, topical tetracaine ( $1 \mathrm{mg} / \mathrm{mL}+$ oxibuprocaine $4 \mathrm{mg} / \mathrm{mL}$ ) eye drops (Anestesico doble Colirccusi ${ }^{\circledR}$, Alcon Cusi $^{\circledR}$ SA, Barcelona, Spain) and intraperitoneal (60 mg $/ \mathrm{kg}$ of Ketamine $+0.25 \mathrm{mg} / \mathrm{kg}$ of Dexmedetomidine) anesthetic. Afterwards, the rats were left to recover in an enriched $2.5 \%$ oxygen atmosphere and were treated with antibiotic ointment (erythromycin $5 \mathrm{mg} / \mathrm{g}$ (Oftalmolosa Cusi ${ }^{\circledR}$ eritromicina, Alcon Cusi ${ }^{\circledR}$ SA, Barcelona, Spain)).

For detailed methodology characteristics, consult the original articles $[27,35,37,38]$.

\subsection{Intraocular Pressure}

IOP measurements using a Tonolab ${ }^{\circledR}$ tonometer (Tonolab, TiolatOy Helsinki, Helsinki, Finland) were recorded in the morning every week. The IOP value was obtained from the average of 18 rebounds. This procedure was accomplished using a sedative mixture of $3 \%$ sevoflurane gas and $1.5 \%$ oxygen for less than $3 \mathrm{~min}$ in order to avoid hypotension effects [39].

\subsection{Optical Coherence Tomography}

SD-OCT (Spectralis, Heidelberg ${ }^{\circledR}$ Engineering, Heidelberg, Germany) was used to analyze the refractive status and the structure of the neuroretina over six months. Recordings were performed at the initial ( 0 weeks), middle (12 weeks) and end time of the study (24 weeks). In addition, an intermediate test was performed at week 8 of the study, which corresponds to 12 weeks of age of the rat. At this age, development and growth of the retina end and the retina reaches maturity [40]. A plane power polymethylmethacrylate (PMMA) contact lens with a thickness of $270 \mu \mathrm{m}$ and a diameter of $5.2 \mathrm{~mm}$ (Cantor+Nissel ${ }^{\circledR}$, Northamptonshire, UK) was adapted to the cornea to obtain high-quality images [41].

Refractive status was measured in diopters (D). The RNFL protocol was used for imaging acquisition. This protocol explores the optic nerve head, which is the most posterior structure of the rat eye, as the eye is elongated. Retinal images were adjusted and acquired by focusing on the retinal vascular structure. The diopters obtained through focusing were then analyzed as the diopter power of the eyeball.

Structural analysis: The RNFL, retina posterior pole (R) and GCL protocol with automatic segmentation were used to quantify neuroretinal thickness (in micrometers). These protocols analyze an area of 1,2 and $3 \mathrm{~mm}$ around the center of the optic disc using 61 scans. Subsequent follow-up examinations were acquired the same location using the eye-tracking software and follow-up application. Biased examinations were discarded or manually corrected by a masked, trained technician if the algorithm had obviously erred. The R and GCL analyzed the 9 ETDRS areas (central area and inner or outer sectors divided into inferior, superior, nasal, and temporal sectors) and the total volume. The RNFL protocol analyzed 6 peripapillary sectors (inferotemporal, temporal, superotemporal, superonasal, nasal, and inferonasal).

For ERG and OCT acquisition, the rats were anesthetized by intraperitoneal administration of $60 \mathrm{mg} / \mathrm{kg}$ of Ketamine $+0.25 \mathrm{mg} / \mathrm{kg}$ of Dexmedetomidine.

\subsection{Electroretinography}

Electroretinography performed to analyze the outer and inner neuroretinal cells' functionality at weeks 0,12 and 24 . The electroretinography device (Roland consult ${ }^{\circledR}$ RETIanimal ERG, Brandenburg an der Havel, Germany) was used to stimulate simultaneously both eyes and explore them in multisteps using the flash scotopic and the photopic negative response (PhNR) protocols. Scotopic test examined rod response: step 1: $-40 \mathrm{~dB}$, $0.0003 \mathrm{cds} / \mathrm{m}^{2}, 0.2 \mathrm{~Hz}$ (20 recordings averaged); step 2: $-30 \mathrm{~dB}, 0.003 \mathrm{cds} / \mathrm{m}^{2}, 0.125 \mathrm{~Hz}$ (18 recordings averaged); step 3: $-20 \mathrm{~dB}, 0.03 \mathrm{cds} / \mathrm{m}^{2}, 8.929 \mathrm{~Hz}$ (14 recordings averaged); step 4: $-20 \mathrm{~dB}, 0.03 \mathrm{cds} / \mathrm{m}^{2}, 0.111 \mathrm{~Hz}$ (15 recordings averaged). Photopic test examined retinal ganglion cell functionality: blue background $470 \mathrm{~nm}, 25 \mathrm{cds} / \mathrm{m}^{2}$ and red LED flash 
$625 \mathrm{~nm}, 0.30 \mathrm{cds} / \mathrm{m}^{2}, 1.199 \mathrm{~Hz}$ (20 recordings averaged). For this purpose, the animals were prepared and the ERG tests were performed as $[27,35]$ described.

\subsection{Statistical Analysis}

Statistical analysis was performed by a blinded researcher. Descriptive analysis of quantitative variables was performed using (mean \pm standard deviation [SD]). As the Kolmogorov-Smirnov test showed a no normal distribution of the variables, comparisons between both the ONT and OHT cohorts and ES and MS groups were conducted using the non-parametric Mann-Whitney U test and comparisons among the ONT, ES and MS cohorts were made using the Kruskal-Wallis H test. Eyes in every cohort were divided into two groups: those with a diopter power higher or lower than $17 \mathrm{D}$ for the ONT eyes and $6 \mathrm{D}$ for the OHT eyes. These sub-groups were used to study the logistic regression to the model so that correlations between refraction and OCT parameters or IOP values could be made. Correlations with the refractive status of the eye, age, OCT thicknesses, and ERG parameters were performed using Spearman correlation coefficient and logistic regression analysis. $p$ values $<0.05$ were considered statistical significative; the Bonferroni correction for multiple comparisons was also calculated to avoid a high false-positive rate.

\section{Results}

A total of 260 eyes of Long-Evans rats were analyzed from two different cohorts: 74 eyes with an IOP lower than $20 \mathrm{mmHg}$ (ONT cohort serving as control), and 186 eyes with an IOP higher than $20 \mathrm{mmHg}$, named the OHT cohort, which in turn was divided into two sub-groups by induced OHT model: 62 eyes based on the ES model and 124 eyes based on the biodegradable MS model.

\subsection{IOP Analysis}

Comparing ONT and OHT cohorts. ONT eyes $(16.09 \pm 2.25 \mathrm{mmHg}$ (range: $13.37-$ $17.62 \mathrm{mmHg})$ ) showed statistically significant $(p<0.05)$ lower IOP than OHT eyes $(23.66$ $\pm 1.40 \mathrm{mmHg}$ (range 21.44-26.74 $\mathrm{mmHg}$ )). Comparing both OHT groups. The ES group presented the highest IOP values up to week 12, after which the trend reversed $(p<0.001)$ (Figure 1a). Analyzing by sex, males suffered from slightly higher IOP values in both the ONT and OHT groups, and reached statistical significance at weeks 8, 10 and $16(p=0.022$, $p<0.001$ and $p=0.023$, respectively) (Figure $1 \mathrm{~b}$ ).

\subsection{Refraction}

Comparing ONT and OHT cohorts. Both the ONT and OHT cohorts experienced a physiological trend toward emmetropia throughout the follow-up, especially over the first weeks of the study; from $35.16 \pm 6.38 \mathrm{D}$ at baseline (Table S1 Supplementary Materials) to $11.87 \pm 3.21 \mathrm{D}$ in the ONT and $11.98 \pm 5.21$ in the OHT at 8 weeks. However, the OHT cohort exhibited lower refractive power that reached statistical significance at week $24(+4.54 \pm 1.5 \mathrm{D}$ in the ONT cohort vs. $+0.88 \pm 2.36 \mathrm{D}$ in the OHT cohort, $p<0.001)$ (Figure 2). Comparing both OHT groups. A small difference between both OHT groups was also detected $(p=0.001)$, with slightly lower dioptric values for the ES group $(+1.66 \pm$ $1.53 \mathrm{D}$ in MS vs. $+0.10 \pm 2.91 \mathrm{D}$ in ES) (Figure 2a). No statistically significant differences were found in refraction between sexes $(p>0.05)$, although males consistently presented lower dioptric power throughout the follow-up, especially in the OHT cohort (Figure $2 b$ ). 

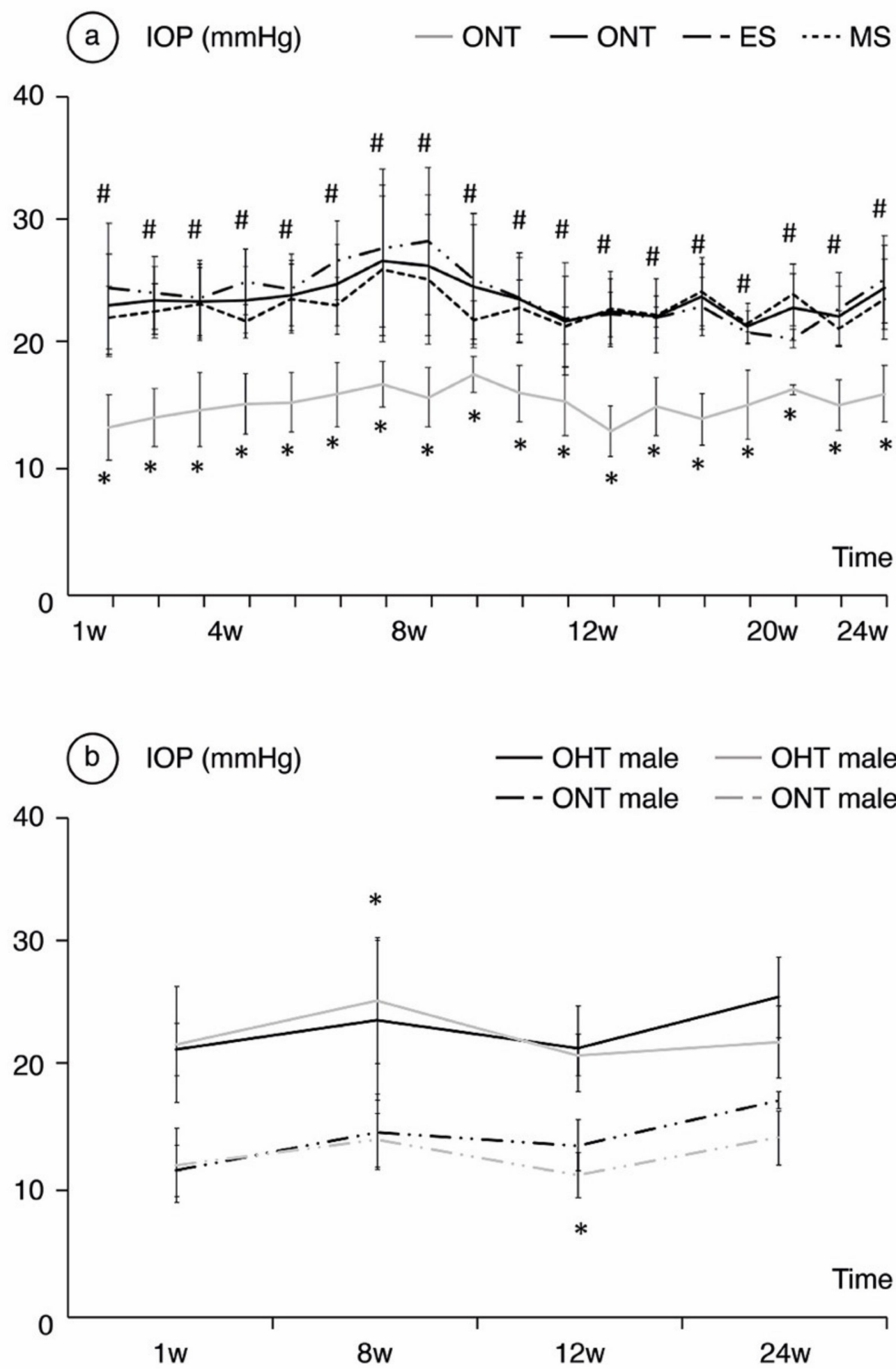

Figure 1. Analysis of intraocular pressure (IOP) in mmHg over the 24-week follow-up comparing the ocular normotension (ONT) and ocular hypertension (OHT) cohorts (a) and comparing both sexes (b). Abbreviations: w: week; ES: episcleral sclerosis group; MS: microspheres group; * statistical differences between the ONT and the OHT cohorts; \#: statistical differences between the ES and MS groups. 
(a) Diopters - ONT - ONT - - ES $\cdots$ MS
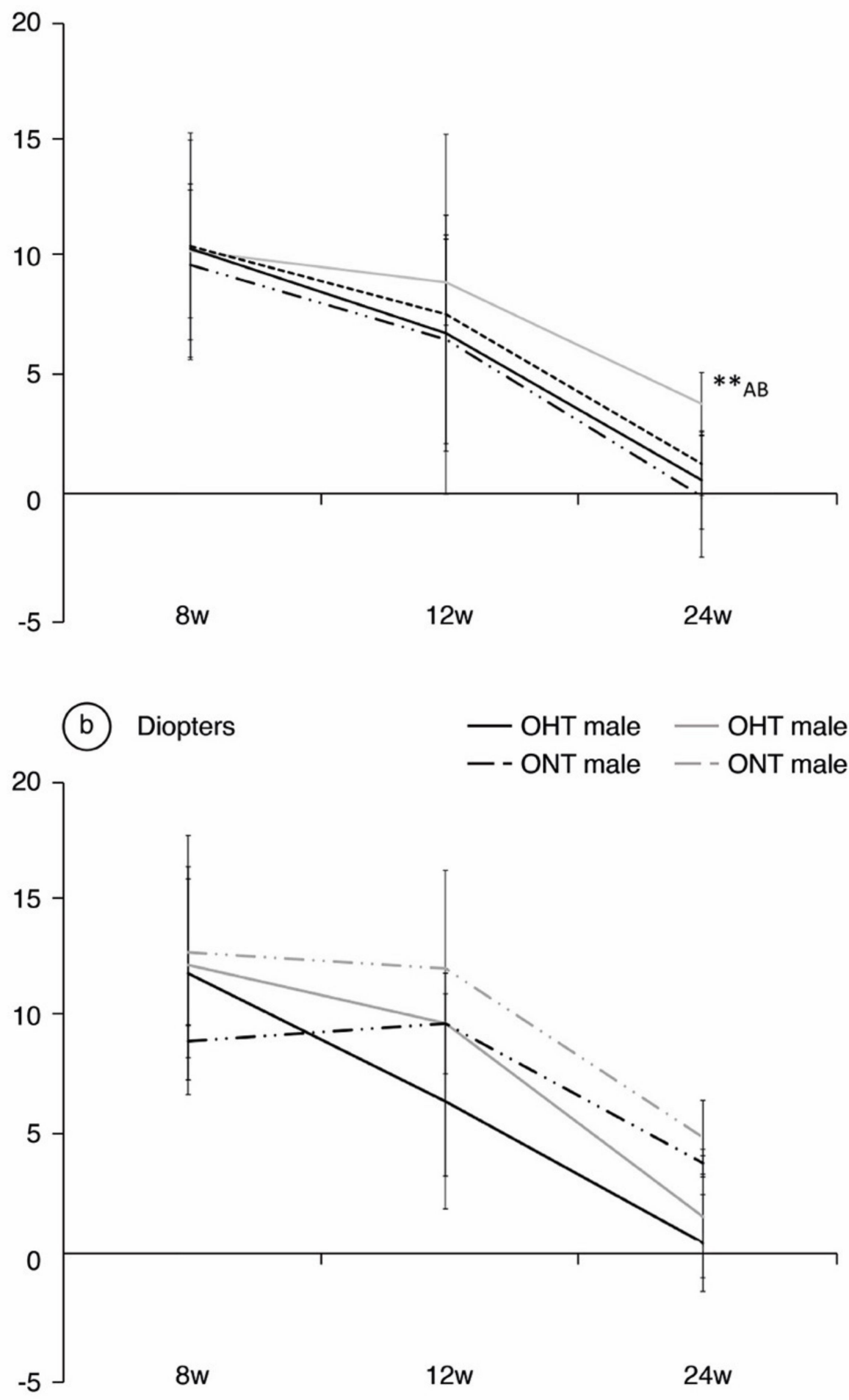

Figure 2. Analysis of refractive power in diopters over the 24-week follow-up, comparing the ocular normotension (ONT) and ocular hypertension (OHT) cohorts (a) and comparing both sexes (b). Abbreviations: w: week; ES: episcleral sclerosis group; MS: microspheres group; **: statistical differences between groups (ONT vs.ES vs. MS) (Kruskal Wallis); A: statistical differences between ONT and ES; B: statistical differences between ONT and MS. 


\subsection{Analysis of the Correlation between Refraction, Ocular Hypertension, and OCT Parameters}

There were no statistically significant correlations between the OCT values and the refractive status of the eye. IOP $>20 \mathrm{mmHg}$ at week 24 was positively correlated to lower dioptric values with a B coefficient of $4.01(p=0.01)$ for the OHT cohort vs. $4.65(p=0.009)$ for the ONT cohort.

\subsection{OCT Analysis}

Comparing ONT and OHT cohorts. The most significant differences were found in week 8 , when the OHT cohort exhibited thicker $\mathrm{R}$ values in the inner temporal sector and all the outer sectors (Table 1). The highest percentage differences by sector also followed the glaucomatous rule inferior $>$ superior $>$ nasal $>$ temporal until week 12 . The ONT cohort experienced a progressive decrease in RNFL thickness over time, and the OHT cohort showed an increase in RNFL thickness at week 12 in both the ES and MS groups (Figure 3). Comparing both OHT groups. Differences between the ONT and OHT cohorts were usually related to the values found in the MS group.

Table 1. Statistically significant differences found by optical coherence tomography parameters analyzed at weeks 8,12 and 24 .

\begin{tabular}{|c|c|c|c|c|c|c|c|c|c|}
\hline Time & $\begin{array}{c}\text { OCT } \\
\text { Protocol }\end{array}$ & Sector & $\begin{array}{l}\text { ONT (Mean } \pm \\
\text { SD in } \mu \mathrm{m})\end{array}$ & $\begin{array}{l}\text { OHT (Mean } \pm \\
\text { SD in } \mu \mathrm{m})\end{array}$ & $\mathrm{D} \%$ & $p^{*}$ & & $\begin{array}{c}\text { OHT Groups } \\
\text { (Mean } \pm \text { SD in } \\
\mu \mathrm{m})\end{array}$ & $p^{+}$ \\
\hline \multirow{8}{*}{$8 W$} & \multirow{6}{*}{$\mathrm{R}$} & Central & $277.20 \pm 17.86$ & $263.21 \pm 22.03$ & -5.05 & 0.022 & $\begin{array}{l}\text { MS } \\
\text { ES }\end{array}$ & $\begin{array}{l}263.80 \pm 22.89 \\
\mathbf{2 6 0 . 3 0} \pm \mathbf{1 7 . 8 6}\end{array}$ & 0.022 \\
\hline & & $\begin{array}{l}\text { Temporal } \\
\text { Inner }\end{array}$ & $244.70 \pm 8.35$ & $251.90 \pm 18.50$ & +2.86 & 0.047 & $\begin{array}{c}\text { MS } \\
\text { ES }\end{array}$ & $\begin{array}{l}\mathbf{2 5 0 . 7 8} \pm \mathbf{1 4 . 8 2} \\
257.50 \pm 31.74\end{array}$ & 0.047 \\
\hline & & $\begin{array}{l}\text { Inferior } \\
\text { Outer }\end{array}$ & $239.90 \pm 6.19$ & $250.50 \pm 11.13$ & +4.23 & 0.003 & $\begin{array}{c}\text { MS } \\
\text { ES }\end{array}$ & $\begin{array}{c}251.40 \pm 11.34 \\
\mathbf{2 4 6 . 0 0} \pm \mathbf{9 . 3 0}\end{array}$ & 0.003 \\
\hline & & $\begin{array}{l}\text { Nasal } \\
\text { Outer }\end{array}$ & $243.30 \pm 4.34$ & $253.60 \pm 12.85$ & +4.06 & 0.002 & $\begin{array}{c}\text { MS } \\
\text { ES }\end{array}$ & $\begin{array}{l}253.96 \pm 11.84 \\
\mathbf{2 5 1 . 9 0} \pm \mathbf{1 7 . 6 0}\end{array}$ & 0.002 \\
\hline & & $\begin{array}{l}\text { Superior } \\
\text { Outer }\end{array}$ & $246.30 \pm 4.19$ & $256.86 \pm 17.28$ & +4.13 & 0.017 & $\begin{array}{c}\text { MS } \\
\text { ES }\end{array}$ & $\begin{array}{l}257.04 \pm 16.69 \\
256.00 \pm 20.89\end{array}$ & 0.017 \\
\hline & & $\begin{array}{c}\text { Temporal } \\
\text { Outer }\end{array}$ & $245.00 \pm 6.48$ & $254.10 \pm 16.10$ & +3.58 & 0.013 & $\begin{array}{c}\text { MS } \\
\text { ES }\end{array}$ & $\begin{array}{l}253.12 \pm 12.17 \\
259.00 \pm 29.37\end{array}$ & 0.013 \\
\hline & \multirow{2}{*}{ GCL } & Central & $19.80 \pm 3.39$ & $17.03 \pm 3.34$ & -13.99 & 0.014 & $\begin{array}{l}\text { MS } \\
\text { ES }\end{array}$ & $\begin{array}{l}16.78 \pm 3.27 \\
18.30 \pm 3.62\end{array}$ & 0.014 \\
\hline & & $\begin{array}{l}\text { Superior } \\
\text { Inner }\end{array}$ & $24.10 \pm 1.85$ & $20.91 \pm 4.03$ & -13.24 & 0.004 & $\begin{array}{l}\text { MS } \\
\text { ES }\end{array}$ & $\begin{array}{l}20.53 \pm 4.04 \\
22.80 \pm 3.61\end{array}$ & 0.004 \\
\hline $12 \mathrm{~W}$ & $\mathrm{R}$ & Central & $285.33 \pm 18.90$ & $266.00 \pm 16.73$ & -6.76 & 0.039 & $\begin{array}{c}\text { MS } \\
\text { ES }\end{array}$ & $\begin{array}{l}267.33 \pm 17.21 \\
\mathbf{2 6 5 . 5 6} \pm \mathbf{1 7 . 6 1}\end{array}$ & 0.039 \\
\hline $24 \mathrm{~W}$ & RNFL & $\begin{array}{c}\text { Nasal } \\
\text { Superior }\end{array}$ & $39.27 \pm 7.25$ & $28.88 \pm 11.99$ & -26.46 & 0.036 & $\begin{array}{l}\text { MS } \\
\text { ES }\end{array}$ & $\begin{array}{l}31.00 \pm 10.66 \\
\mathbf{2 7 . 6 0} \pm \mathbf{1 3 . 1 0}\end{array}$ & 0.050 \\
\hline
\end{tabular}

OCT: optical coherence tomography; R: retina; GCL: ganglion cell layer complex; RNFL: retinal nerve fiber layer; W: week; ONT: ocular normotension cohort; OHT: ocular hypertension cohort; ES: episcleral sclerosis group; MS: microspheres group; D\%: differences in percentage; $p$ : statistical differences $(<0.05):{ }^{*} \mathrm{U}$ Mann Whitney; ${ }^{\dagger}$ Kruskal Wallis; the lowest thickness values are highlighted in bold. 

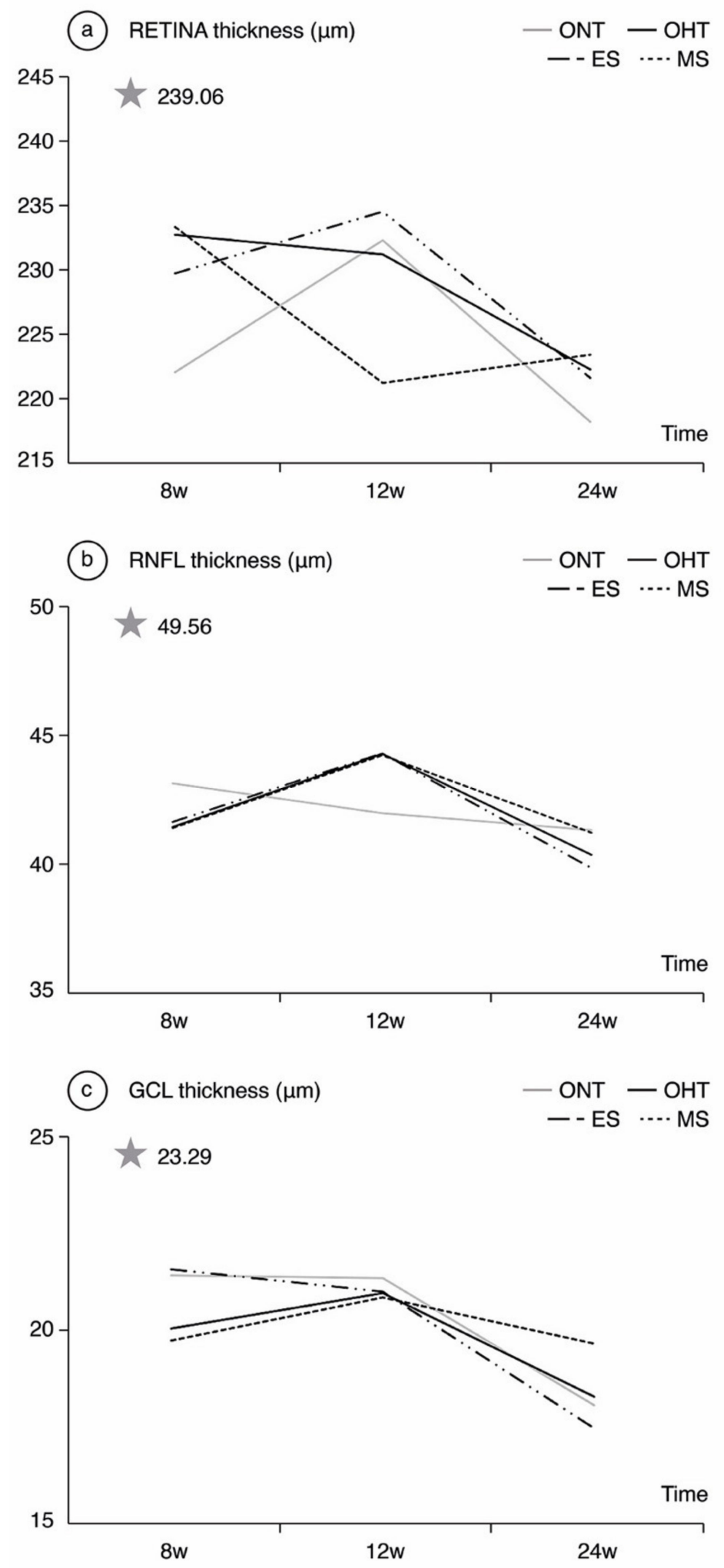

Figure 3. Neuroretinal thickness measured by optical coherence tomography in both the ocular normotension and ocular hypertension cohorts and the ocular hypertension sub-groups at 8, 12, 24 weeks follow-up. (a) Retina thickness, (b) Retina nerve fiber layer thickness, (c) Ganglion cell layer thickness. The analysis is based on the mean values of all the OCT sectors. ONT: ocular normotension cohort; OHT: ocular hypertension cohort; ES: episcleral sclerosis group; MS: microspheres group; RNFL: retinal nerve fiber layer; GCL: ganglion cell layer; $\mu$ m: thickness in micrometers; W: week; star: baseline thickness. 


\subsection{ERG Analysis}

Comparing ONT and OHT cohorts. The ONT cohort presented wider variability in subject responses compared to the OHT cohort (Figures 4-6). In the OHT cohort, a stronger response was found in scotopic and photopic conditions in week 12, with shorter latencies (Figures $4 a, 5 a$ and $6 a$ ) and greater amplitudes (Figures $4 b$, 5b and $6 b$ ). However, maintenance of hypertension over time (week 24) decreased the electrical signal in the ERG, which almost matched the ONT values, especially in the later stages. Comparing both OHT groups. Generally, the MS groups exhibited faster latency and greater amplitude in week 12 in scotopic and photopic conditions, although this trend reversed in week 24.

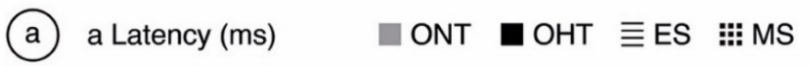

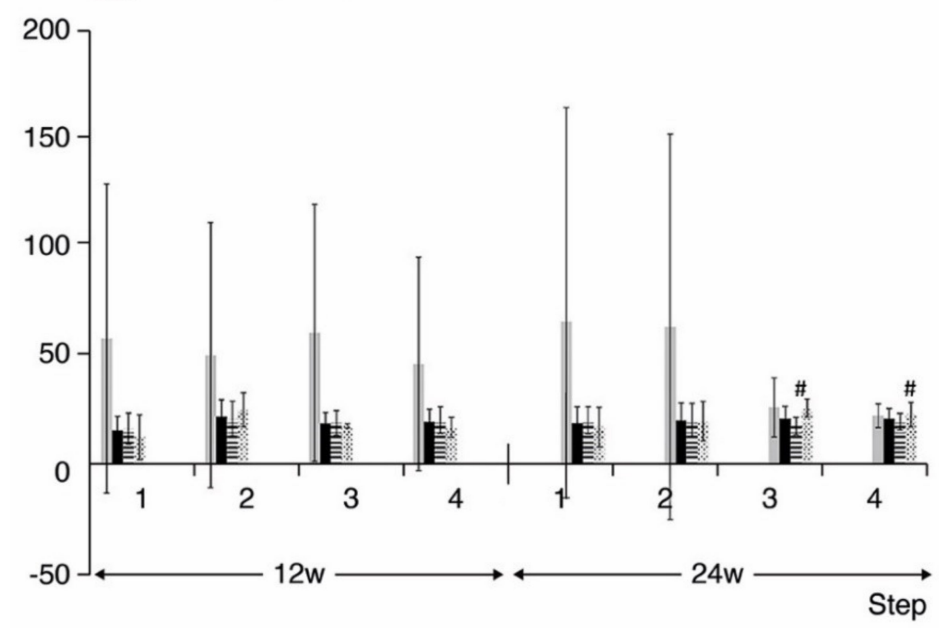

(b) a Amplitude $(\mu \mathrm{V}) \quad$ ONT $\mathbf{D O H T} \equiv \mathrm{ES}$ :\#

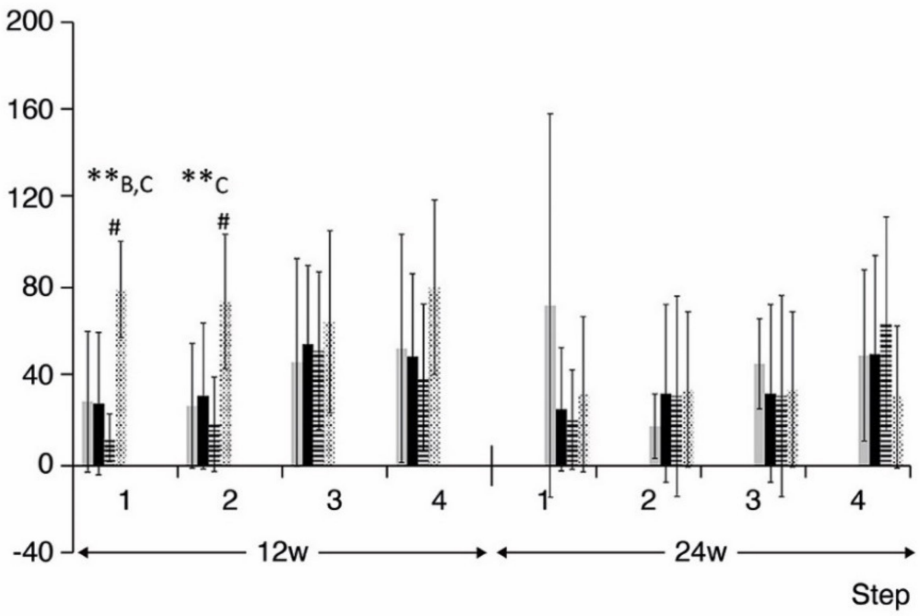

Figure 4. a-wave electroretinographic response in both the ocular normotension and ocular hypertension cohorts and the ocular hypertension sub-groups at weeks 12 and 24. (a) a-latency in milliseconds of photoreceptors under scotopic conditions. (b) a-amplitude in microvolts of photoreceptors under scotopic conditions. Abbreviations: ONT: ocular normotension group; OHT: ocular hypertension group; ES: episcleral sclerosis group; MS: microspheres group; w: week; ms: milliseconds; $\mu \mathrm{V}$ : microvolts; **: statistical differences between groups (ONT vs. ES vs. MS) (Kruskal-Wallis); \#: statistical differences between the ES and MS groups; A: statistical differences between ONT and ES; B: statistical differences between ONT and MS; C: statistical differences between ES and MS. Scotopic test (rod response): step 1: $-40 \mathrm{~dB}, 0.0003 \mathrm{cds} / \mathrm{m}^{2}, 0.2 \mathrm{~Hz}$ (20 recordings averaged); step 2: $-30 \mathrm{~dB}, 0.003 \mathrm{cds} / \mathrm{m}^{2}, 0.125 \mathrm{~Hz}$ (18 recordings averaged); step 3: $-20 \mathrm{~dB}, 0.03 \mathrm{cds} / \mathrm{m}^{2}, 8.929 \mathrm{~Hz}(14$ recordings averaged); step $4:-20 \mathrm{~dB}, 0.03 \mathrm{cds} / \mathrm{m}^{2}, 0.111 \mathrm{~Hz}$ (15 recordings averaged). 
(a) b Latency (ms) $\quad$ ONT $\square \mathrm{OHT} \equiv \mathrm{ES}$ \#MS

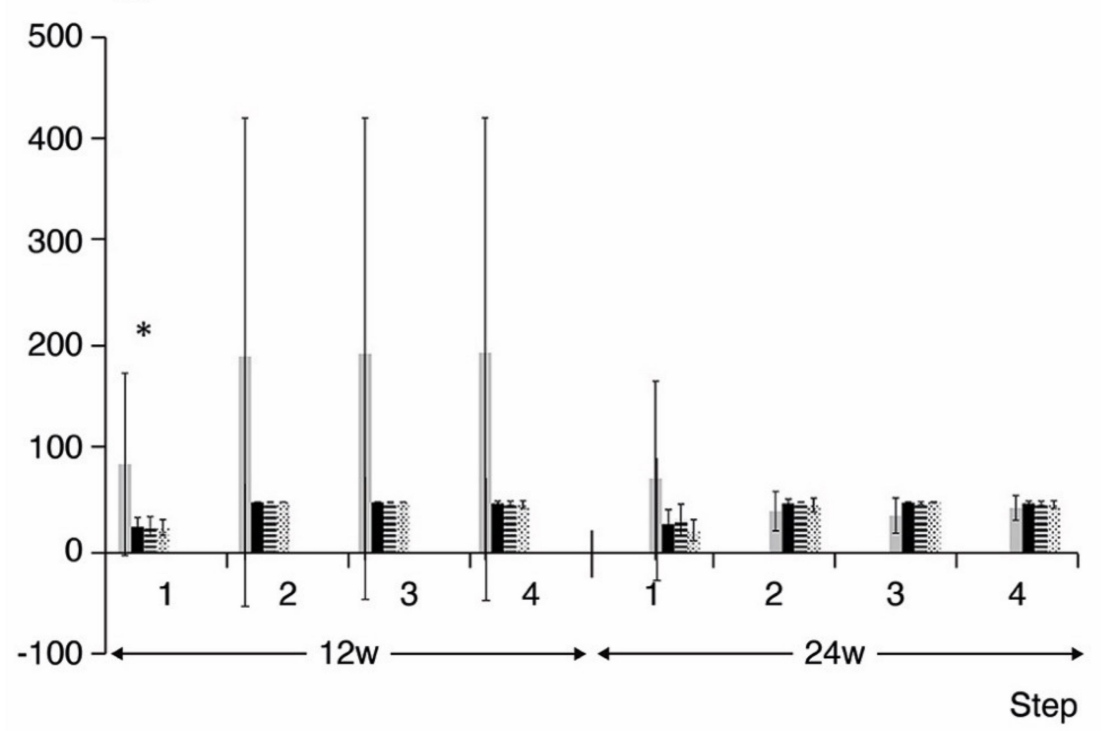

(b) b Amplitude $(\mu \mathrm{V}) \quad \square$ ONT $\mathbf{\square O H T} \equiv \mathrm{ES}$ \#MS

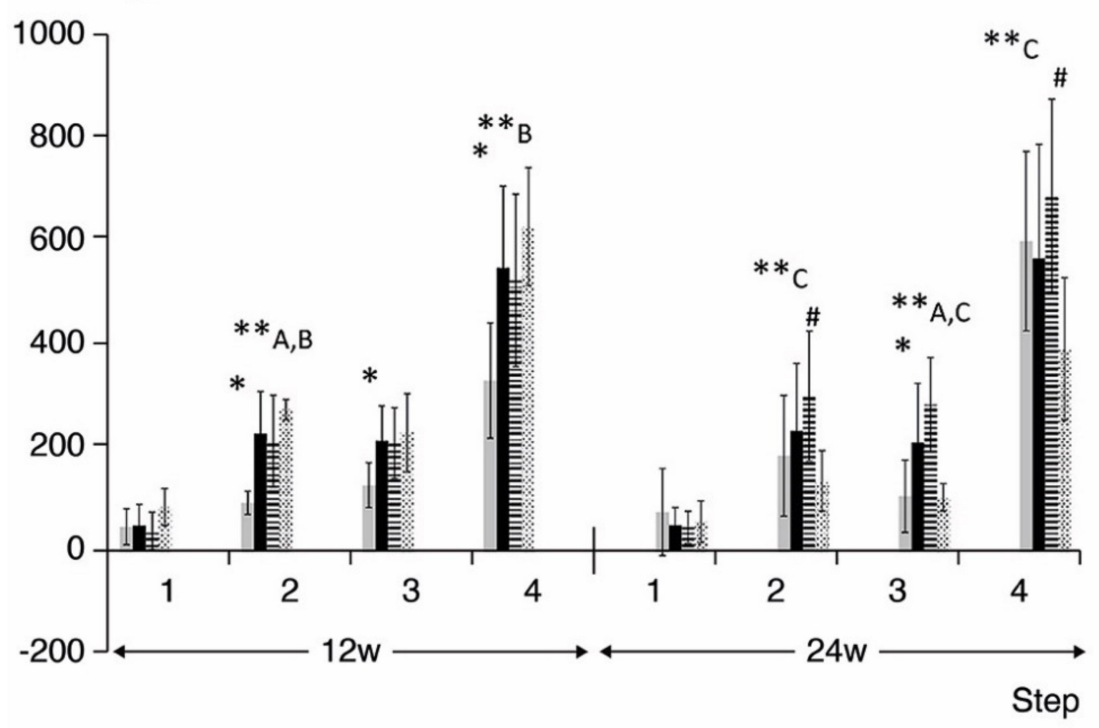

Figure 5. b-wave electroretinographic response in both the ocular normotension and ocular hypertension cohorts and the ocular hypertension sub-groups at weeks 12 and 24. (a) b-latency in milliseconds of intermediate cells under scotopic conditions. (b) b-amplitude in microvolts of intermediate cells under scotopic conditions. ONT: ocular normotension group; OHT: ocular hypertension group; ES: episcleral sclerosis group; MS: microspheres group; w: week; ms: milliseconds; $\mu \mathrm{V}$ : microvolts; * statistical differences between the ONT and OHT cohorts. ${ }^{* *}$ : statistical differences between groups (ONT vs. ES vs. MS) (Kruskal-Wallis); \#: statistical differences between the ES and MS groups; A: statistical differences between ONT and ES; B: statistical differences between ONT and MS; C: statistical differences between ES and MS. Scotopic test (rod response): step 1: $-40 \mathrm{~dB}, 0.0003 \mathrm{cds} / \mathrm{m}^{2}$, $0.2 \mathrm{~Hz}$ (20 recordings averaged); step 2: $-30 \mathrm{~dB}, 0.003 \mathrm{cds} / \mathrm{m}^{2}, 0.125 \mathrm{~Hz}$ (18 recordings averaged); step 3: $-20 \mathrm{~dB}, 0.03 \mathrm{cds} / \mathrm{m}^{2}, 8.929 \mathrm{~Hz}$ (14 recordings averaged); step 4: $-20 \mathrm{~dB}, 0.03 \mathrm{cds} / \mathrm{m}^{2}, 0.111$ $\mathrm{Hz}$ (15 recordings averaged). 


\section{(a) PhNR Latency (ms) $\square$ ONT $\mathbf{D O H T} \equiv \mathrm{ES}$ \# MS}

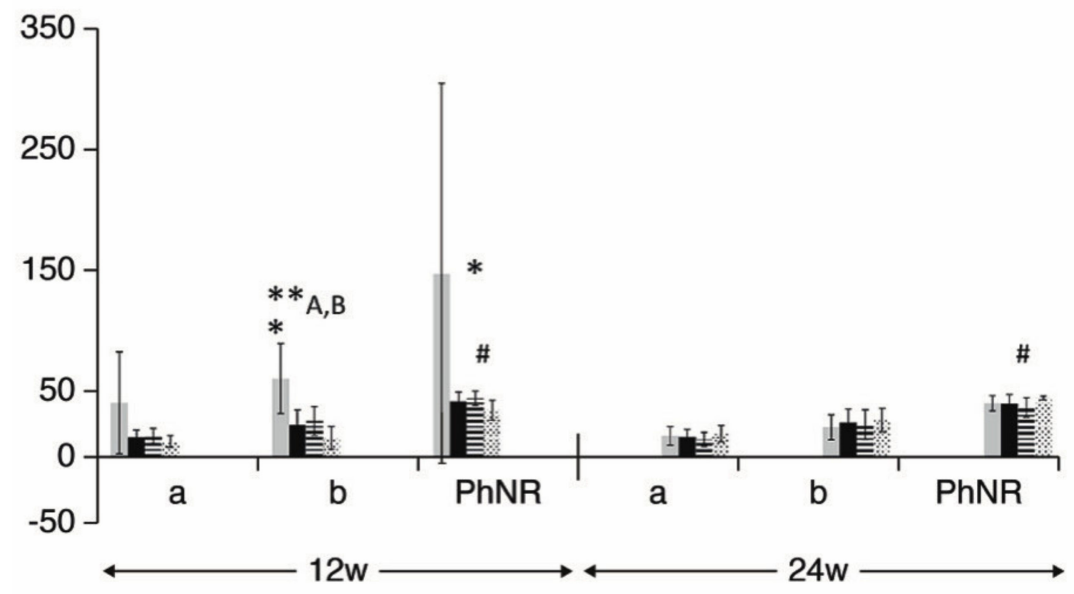

\section{(b) PhNR Amplitude $(\mu \mathrm{V}) \square \mathrm{ONT}$-OHT $\equiv$ ES \# MS}

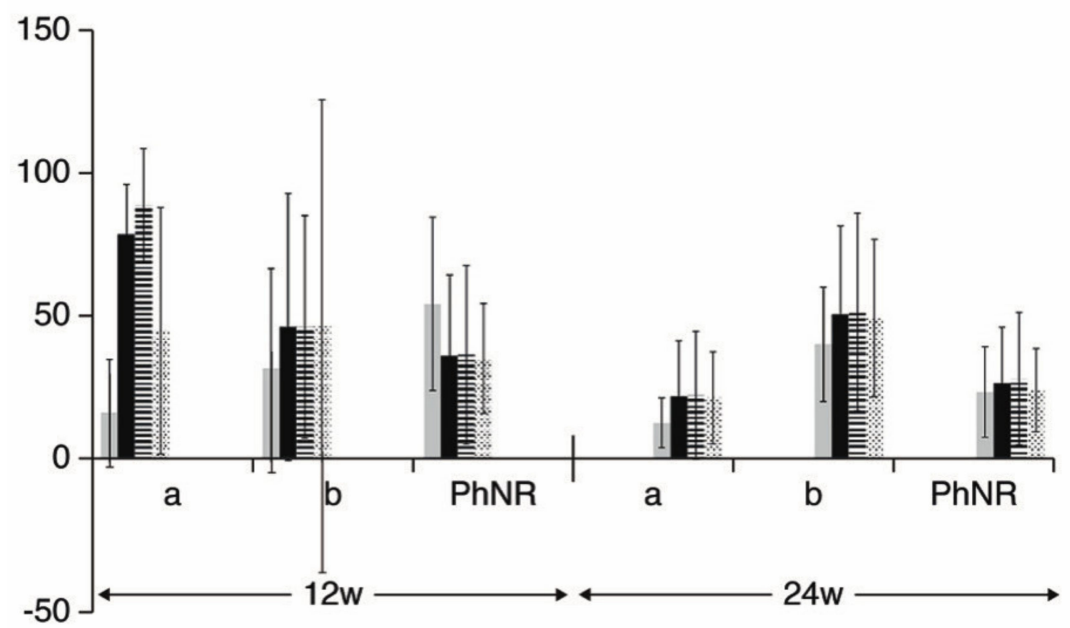

Figure 6. PhNR wave electroretinographic response in both the ocular normotension and ocular hypertension cohorts and the ocular hypertension sub-groups at weeks 12 and 24. (a) PhNR latency of in milliseconds under photopic conditions. (b) PhRN amplitude in microvolts under photopic conditions. Abbreviations: ONT: ocular normotension group; OHT: ocular hypertension group; ES: episcleral sclerosis group; MS: microspheres group; w: week; ms: milliseconds; $\mu \mathrm{V}$ : microvolts; * statistical differences between the ONT and OHT cohorts. ${ }^{* *}$ : statistical differences between groups (ONT vs. ES vs. MS) (Kruskal-Wallis); \#: statistical differences between the ES and MS groups; A: Statistical differences between ONT and ES; B: Statistical differences between ONT and MS. Photopic test: blue background $470 \mathrm{~nm}, 25 \mathrm{cds} / \mathrm{m}^{2}$ and red LED flash $625 \mathrm{~nm}, 0.30 \mathrm{cds} / \mathrm{m}^{2}, 1.199 \mathrm{~Hz}(20$ recordings averaged). a: photoreceptors response; b: intermediate cells response; PhNR: ganglion cells response.

\section{Discussion}

The effects of ocular hypertension have been described in a multitude of short-term animal studies, generally up to a maximum of 8 weeks of follow-up [37,42-44]. This study analyzes the effect of chronic OHT maintained over time focusing the study between 8 and 24 weeks of chronicity. To our knowledge, this is the first retrospective longitudinal 24-week study carried out in young-adult Long-Evans rats in vivo using automatically segmented OCT images that analyze the effect of mild-moderate OHT (between $20-30 \mathrm{mmHg}$ ) on refraction from the neuroretinal perspective (structure and function) and employs two 
different OHT-inducing models (ES vs. MS), in comparison to healthy controls. This allows us to analyze the neurodegenerative process in conditions of chronic OHT on myopia.

\subsection{Refractive Analysis}

The total optic power of the eye depends on factors such as axial length, corneal power and lens power. At birth, human eyes are usually hyperopic, and afterwards there is a trend toward emmetropia as the cornea structure stabilizes, though axial length may continue to grow until the second decade. However, in high myopia there is continuous, progressive axial elongation throughout life, possibly due to genetic, environmental and behavioral factors [45,46]. Although all the mechanisms involved in this progressive enlargement of the eyeball are not completely understood, the effect of IOP on axial elongation of the posterior pole [47,48], the importance of sclera stiffness [49] and the dynamic responses of the sclera after a chronic increase in IOP [50] have been factors involved in the emmetropization process.

Ocular hypertension in congenital glaucoma occurs in developing loose tissue, meaning the sclera still exhibit great plasticity and stretch, increasing axial length [51]. This is similar to what occurs in high myopia [52,53], which supports the incidence of high myopia in adulthood [54]. When ocular hypertension occurs in older ages, scleral tissues are more rigid and stiffen [55], explaining the greater glaucomatous damage (IOP spikes are more poorly mitigated by less elastic sclera), the outward shift of the lamina cribosa and remodeling of connective tissue [56], and the deeper anterior chamber described in both the ES model and DBA/2J glaucomatous mice (not observed in OHT models using cauterization, probably due to the experimental intervention itself) $[57,58]$. Indeed, there is increasing evidence about the development of delayed and sustained OHT associated with repeated intravitreal anti-vascular endothelial growth factor injections in retinal diseases, such as age-related macular degeneration $[59,60]$. Several structure optic nerve head manifestations after intravitreal volume injections have been lately described as a mechanical displacement of the optic nerve head and canal expansion, with a widening and deepening of the optic, a prelaminar tissue thinning and a Bruch membrane opening expansion, suggesting structural changes after IOP and volume increase in aged patients, with rigid sclera [61]. Our experiments started when the rats were 4 weeks old, so they should not be considered either adults or newborns, but young rats. The refractive status was likewise not consistent with high myopia $(-6 \mathrm{D})$ so, in our opinion, eye elongation was presumably more similar to what occurs in human POAG. Our OHT models supported the pre-existing evidence, as the ES cohort presented higher IOP, greater axonal damage, and lower dioptric power.

This study demonstrated the influence of sustained mild-moderate IOP on the emmetropization process. The baseline optical power was $35.16 \pm 6.28 \mathrm{D}$ (as [62] reported), with a progressive trend toward emmetropia in both ONT and OHT eyes. However, the statistically significant correlations to refraction were found only with mild-moderate OHT at week 24 in both ES and MS models, and were not found with functional or structural alterations. Therefore, a chronic sustained increase in IOP was considered the main risk factor involved in the loss of refractive power in OHT eyes. In this regard, animal and human studies also correlated hypotensive treatments such as trabeculectomy [63] and topical drugs such as latanoprost [16] to a decrease in total axial length, although studies with drugs such as timolol showed inconsistencies in both human [18] and animal models [17]. One of the next steps worth studying in future prospective studies is the influence of prompt normalization of IOP on refraction in these OHT models as a possible treatment for myopia.

Nowadays, high myopia is increasingly prevalent in populations that carry out nearvision activities $[64,65]$. Sharp focus on a near image requires concomitant activation of both inferior and medial rectus muscles, and the subsequent compression of the eyeball by both muscles may cause an increase in IOP [66], similar to what happens in other compressive pathologies $[67,68]$. In addition, greatest drainage of aqueous humor occurs mainly via 
the nasal and lower episcleral veins [69-73], so sustained compression of these muscles at these locations during near-vision activities for extended periods of time would increase IOP. Moreover, in childhood and early adulthood, when eye elongation is easily achieved as it is less rigid, refractive power may consequently decrease [74]. Indeed, lower dioptric power would require higher demand for more synkinesis accommodation/convergence, creating a vicious circle [75]. Current studies with atropine drops are showing promising results in controlling myopia by producing a reversible anti-accommodative effect [76,77], and the dose-dependent anti-muscarinic effect on the smooth muscles of the episcleral veins could also balance the outflow.

In this study, the ES model, in which the outflow of the episcleral veins is limited, induced higher IOP and higher negative dioptric power. MS model produced a progressive alteration of the trabecular meshwork due to the mechanical clogging [78], but in a slower and more progressive structural and functional damage, more similar to that of the human POAG, and a lower negative dioptric power [35]. Moreover, a trend toward higher dioptric power was found in females, as well as lower levels of IOP, attributed to estrogens [79]. Scleral stiffness depends on choroidal vascular factors, among others, so estrogens could contribute to vascular protection against peripapillary rigidity and posterior location of the optic nerve head, which could explain the higher myopia rates found in male rats.

To our knowledge, this is the first study that longitudinally monitors eye growth in vivo (by indirect study of optical power) using non-invasive, simple, objective OCT technology that demonstrates progressive myopization in glaucomatous rats, influenced by sex and the OHT-inducing model. Refractive study in small animals usually requires invasive, expensive or low-reliability techniques such as enucleation, magnetic resonance imaging or ultrasound biomicroscopy, respectively, which makes longitudinal studies with the same animal impracticable. Previous ocular biometric studies using OCT on healthy $[80,81]$ and glaucomatous mice $[50,82]$ have been performed. However, only one study of healthy rats measured biometrics in vivo using high-resolution A-scan ultrasonography [62], and no convincing evidence of emmetropization during normal eye development was detected. Similar results were found in this study, in which the ONT cohort never experienced negative optical power (myopia), unlike rats in the OHT cohort.

Analysis of refractive status constitutes a methodological limitation. As it was a retrospective study, it was not designed to analyze axial length, so the refractive status of the eye was measured with the OCT focuser, which improves image quality when acquiring OCT scans. The value obtained via this method is acceptable, but less accurate than axial length. Moreover, the use of a rigid contact lens for OCT imaging from which the retinal focusing data were obtained, introduces a tear lens, whose power will vary according to the mismatch between the fixed, posterior radius of curvature of the lens and anterior corneal radius, which can be expected to increase with age, and may also be altered in response to intracameral injections of MS. However, the lens was used in each examination, so the induced error would be constant, and the refractive trend found in our results would be constant throughout the study.

\subsection{Structural Analysis}

A decrease in RNFL thickness is a common feature in both myopic [83] and glaucomatous patients, though RNFL segmentation errors in automated SD-OCT analysis are frequent in myopia [84]. The good correlation observed between GCL and RNFL analysis has surpassed total retinal quantification, and GCL analysis has emerged as a more appropriate imaging tool for detecting early glaucomatous progression in myopic patients [85].

When analyzing the R, RNFL and GCL values, OCT protocols were performed around the optic disc as rats do not have macula, so central values could lead to misinterpretations. This is one of the main reasons why correlations to human retina are limited. As regards general trends, differences in R thickness between the ONT and OHT cohorts were seen up to week 8 , although they then decreased through week 24 , possibly due to a neurodegener- 
ative process, with an initial inflammatory response that causes an increase in thickness (activated microglia and other inflammatory mediators [31]), and a final atrophic pattern. The greater thickness found in external sectors of peripheral retina could be attributed to peripheral immune infiltration [31]. On the other hand, it is important to highlight that there were no correlations between refraction and R, GCL, and RNFL thicknesses. IOP was therefore the most important factor modifying retinal thickness, meaning that the RNFL thinning observed in the OHT cohorts in week 24 was secondary to neurodegeneration rather than a stretching of the retinal tissue. Hence, OCT has demonstrated its reliability when analyzing retinal structures in neurodegenerative diseases [28], even during the emmetropization process.

Comparing both OHT groups, the ES group exhibited thicker R, RNFL and GCL values at week 8 , but the thickness loss rate was also higher over time, reaching the lowest thickness at the end of follow-up. As this cohort suffered from higher IOP levels, these eyes could have suffered intense damage (a more extreme response) at GCL level that explains this drop. Conversely, RNFL analysis of the OHT cohorts showed an initial increase in thickness until week 12, after which the trend reversed in both groups, although it did so more dramatically in the ES group, supporting this theory.

The lack of histological studies is the main handicap of structural analysis, but several studies reflected the good correlation between immunohistochemistry and OCT thicknesses, making SD-OCT reliable for research in retinal degeneration [28]. Another limitation of this study was not having considered the lateral magnification that occurs as the anterior chamber increases, which overstates the retinal thickness. Most myopic eyes may therefore have even smaller retinal thicknesses [86].

\subsection{Functional Analysis}

ERG showed supranormal responses in the OHT cohorts, especially in the MS group in week 12. These outcomes were also observed in other animal studies with acute [43,47] and chronic [48] non-ischemic increases in IOP. This noxa could lead to initial hyperstimulation of the neuronal structures, especially bipolar and intermediate cells, while the process is neither ischemic nor chronic. In other words, we are possibly witnessing the beginning of the disease in an early or even reversible phase. However, this initially stronger electrical response disappeared at week 24 , suggesting the decline of this phenomenon, probably due to ischemia or neurodegenerative damage, as occurs in POAG. It has also been hypothesized that the supranormal ERG responses could be related to the increase in illuminated retinal area during the test (greater axial length means greater retinal area, compared to normal axial length), though this hypothesis could not explain all the ERG findings [44], among them the fact that the supranormal electrical response is not sustained over time, but only when the eye is more hyperopic (in early phases of the study). In contrast, human studies showed a negative correlation between axial length (but not refractive error) and the values of ERG responses in healthy adults [20,87], as occurs here at later stages. This pattern of electrical response was more extreme in the MS group and was consistent throughout the steps, showing a coherent pattern of electrical behavior in photoreceptor and bipolar cells. However, because the ES model is more aggressive, this suprasignal could have occurred before week 12 in the ES model. We may therefore have witnessed an ongoing decay phase.

This functional behavior could be somehow correlated to the structural OCT findings of this study. At week 12, the GCL and RNFL are not as damaged, and their status is reversible, which could be correlated to the ERG hyperresponsive pattern. This could be supported by a previous study (also using Long-Evans rats) with a similar electrical pattern after chronic IOP elevation (by circumlimbal suture) that returned to baseline after suture removal [88]. This functional damage was not correlated with structural damage to GCL density, but with a reduction in the RNFL in week 15 in the post-hoc analysis [88]. Again, it is important to note that the only parameter that was statistically correlated to the refraction 
was IOP $>20 \mathrm{mmHg}$, not the ERG parameters. Our results therefore suggest that refractive status also appears to be an independent factor for ERG tests when analyzing POAG.

\section{Conclusions}

In this article, we pointed out the relationship between ocular hypertension and refraction over time. Visual disturbances in glaucomatous patients could also be associated with a progressive negative refractive error, in addition to the neurodegenerative damage associated with glaucoma, so frequent assessment of refraction may be important in these patients over time. The study of functional and structural tests in early and late stages in two different POAG models produced a deeper understanding of the pathophysiological retinal damage caused by the increase in IOP, with an initial increase in electrical signal associated with a thickening pattern detected using OCT, followed by functional and structural impairment. In addition, the lack of correlation between the refractive status of the eye and the structure and function of the retina provided further insight into the usefulness of OCT and ERG in relation to the emmetropia process.

Supplementary Materials: The following are available online at https:/ /www.mdpi.com/article/10 $.3390 / \mathrm{jcm} 10163697 / \mathrm{s} 1$, Table S1: Baseline characteristics of the study.

Author Contributions: Conceptualization, M.J.R., L.E.P. and E.G.-M.; methodology, M.J.R., S.M.-M. and E.G.-M.; software, E.G.-M.; validation, M.J.R., and E.G.-M.; formal analysis E.G.-M.; investigation, S.M.-M., T.M.-R., M.S., M.J.R.; resources, L.E.P., J.G.F., I.B.-O., R.H.-V., E.G.-M.; data curation, S.M.-M., T.M.-R., M.S., M.J.R., D.G.-H.; writing—original draft preparation, S.M.-M.; writing-review and editing, S.M.-M. and M.J.R.; visualization, S.M.-M. and M.J.R.; supervision, E.G.-M., M.J.R.; project administration, E.G.-M., L.E.P., M.J.R.; funding acquisition, E.G.-M., L.E.P. All authors have read and agreed to the published version of the manuscript.

Funding: This research was funded by Rio Hortega Research Grants M17/00213, PI17/01726, PI17/01946 and PI20/00437 (Carlos III Health Institute), and by MAT2017-83858-C2-2, MAT201783858-C2-1 and PID2020-113281RB-C2-2 MINECO/AEI/ERDF, EU, UCM Research Group 920415, ISCIII-FEDER “Una manera de hacer Europa” RETICS Oftared, RD16/0008/0004, RD16/0008/0009, and RD16/0008/029. D.G.H. acknowledges a UCM-Santander fellowship (CT17/17-CT17-18).

Institutional Review Board Statement: The study was conducted according to the guidelines of the Declaration of Helsinki, and approved by the Ethics Committee for Animal Research (PI34/17) and were carried out in strict accordance with the Association for Research in Vision and Ophthalmology's Statement for the use of Animals.

Informed Consent Statement: Not applicable.

Data Availability Statement: The data are available only upon request to the corresponding author.

Conflicts of Interest: The authors declare no conflict of interest. The funders had no role in the design of the study; in the collection, analyses, or interpretation of data; in the writing of the manuscript, or in the decision to publish the results.

\section{References}

1. Agis Investigators. The Advanced Glaucoma Intervention Study (AGIS): 7. The relationship between control of intraocular pressure and visual field deterioration.The AGIS Investigators. Am. J. Ophthalmol. 2000, 130, 429-440. [CrossRef]

2. Shim, S.H.; Sung, K.R.; Kim, J.M.; Kim, H.T.; Jeong, J.; Kim, C.Y.; Lee, M.Y.; Park, K.H. Korean Ophthalmological Society the Prevalence of Open-Angle Glaucoma by Age in Myopia: The Korea National Health and Nutrition Examination Survey. Curr. Eye Res. 2017, 42, 65-71. [CrossRef] [PubMed]

3. Wong, T.Y.; Klein, B.E.K.; Klein, R.; Knudtson, M.; Lee, K.E. Refractive errors, intraocular pressure, and glaucoma in a white population. Ophthalmology 2003, 110, 211-217. [CrossRef]

4. Xu, L.; Wang, Y.; Wang, S.; Wang, Y.; Jonas, J.B. High myopia and glaucoma susceptibility the Beijing Eye Study. Ophthalmology 2007, 114, 216-220. [CrossRef] [PubMed]

5. Ikuno, Y. Overview of the Complications of High Myopia. Retina 2017, 37, 2347-2351. [CrossRef]

6. Saw, S.M.; Gazzard, G.; Shin-Yen, E.C.; Chua, W.H. Myopia and associated pathological complications. Ophthalmic Physiol. Opt. 2005, 25, 381-391. [CrossRef] 
7. Holden, B.A.; Fricke, T.R.; Wilson, D.A.; Jong, M.; Naidoo, K.S.; Sankaridurg, P.; Wong, T.Y.; Naduvilath, T.J.; Resnikoff, S. Global Prevalence of Myopia and High Myopia and Temporal Trends from 2000 through 2050. Ophthalmology 2016, 123, 1036-1042. [CrossRef]

8. Kim, T.-W.; Kim, M.; Weinreb, R.N.; Woo, S.J.; Park, K.H.; Hwang, J.-M. Optic Disc Change with Incipient Myopia of Childhood. Ophthalmology 2012, 119, 21.e3-26.e3. [CrossRef] [PubMed]

9. Ng, D.S.C.; Cheung, C.Y.L.; Luk, F.O.; Mohamed, S.; Brelen, M.E.; Yam, J.C.S.; Tsang, C.W.; Lai, T.Y.Y. Advances of optical coherence tomography in myopia and pathologic myopia. Eye 2016, 30, 901-916. [CrossRef]

10. Leung, C.K.S.; Mohamed, S.; Leung, K.S.; Cheung, C.Y.L.; Chan, S.L.W.; Cheng, D.K.Y.; Lee, A.K.C.; Leung, G.Y.O.; Rao, S.K.; Lam, D.S.C. Retinal nerve fiber layer measurements in myopia: An optical coherence tomography study. Investig. Ophthalmol. Vis. Sci. 2006, 47, 5171-5176. [CrossRef] [PubMed]

11. Schmid, K.L.; Hills, T.; Abbott, M.; Humphries, M.; Pyne, K.; Wildsoet, C.F. Relationship between intraocular pressure and eye growth in chick. Ophthalmic Physiol. Opt. 2003, 23, 25-33. [CrossRef] [PubMed]

12. Read, S.A.; Collins, M.J.; Annis-Brown, T.; Hayward, N.M.; Lillyman, K.; Sherwin, D.; Stockall, P. The short-term influence of elevated intraocular pressure on axial length. Ophthalmic Physiol. Opt. 2011, 31, 398-403. [CrossRef] [PubMed]

13. Tokoro, T.; Funata, M.; Akazawa, Y. Influence of intraocular pressure on axial elongation. J. Ocul. Pharmacol. 1990, 6, 285-291. [CrossRef] [PubMed]

14. McBrien, N.A.; Jobling, A.I.; Gentle, A. Biomechanics of the Sclera in Myopia: Extracellular and Cellular Factors. Optom. Vis. Sci. 2009, 86, E23-E30. [CrossRef]

15. McMonnies, C.W. An examination of the baropathic nature of axial myopia. Clin. Exp. Optom. 2014, 97, 116-124. [CrossRef] [PubMed]

16. El-Nimri, N.W.; Wildsoet, C.F. Effects of topical latanoprost on intraocular pressure and myopia progression in young guinea pigs. Invest. Ophthalmol. Vis. Sci. 2018, 59, 2644-2651. [CrossRef] [PubMed]

17. Schmid, K.L.; Abbott, M.; Humphries, M.; Pyne, K.; Wildsoet, C.F. Timolol lowers intraocular pressure but does not inhibit the development of experimental myopia in chick. Exp. Eye Res. 2000, 70, 659-666. [CrossRef] [PubMed]

18. Huang, J.; Wen, D.; Wang, Q.; McAlinden, C.; Flitcroft, I.; Chen, H.; Saw, S.M.; Chen, H.; Bao, F.; Zhao, Y.; et al. Efficacy comparison of 16 interventions for myopia control in children: A network meta-analysis. Ophthalmology 2016, 123, 697-708. [CrossRef]

19. Patel, N.B.; Garcia, B.; Harwerth, R.S. Influence of anterior segment power on the scan path and RNFL thickness using SD-OCT. Investig. Ophthalmol. Vis. Sci. 2012, 53, 5788-5798. [CrossRef] [PubMed]

20. Sachidanandam, R.; Ravi, P.; Sen, P. Effect of axial length on full-field and multifocal electroretinograms. Clin. Exp. Optom. 2017, 100, 668-675. [CrossRef] [PubMed]

21. Biswas, S.; Lin, C.; Leung, C.K.S. Evaluation of a myopic normative database for analysis of retinal nerve fiber layer thickness. JAMA Ophthalmol. 2016, 134, 1032-1039. [CrossRef]

22. Biswas, S.; Jhanji, V.; Leung, C.K.S. Prevalence of glaucoma in myopic corneal refractive surgery candidates in Hong Kong China. J. Refract. Surg. 2016, 32, 298-304. [CrossRef] [PubMed]

23. Shoji, T.; Nagaoka, Y.; Sato, H.; Chihara, E. Impact of high myopia on the performance of SD-OCT parameters to detect glaucoma. Graefe's Arch. Clin. Exp. Ophthalmol. 2012, 250, 1843-1849. [CrossRef]

24. Neufeld, A.H.; Gachie, E.N. The inherent, age-dependent loss of retinal ganglion cells is related to the lifespan of the species. Neurobiol. Aging 2003, 24, 167-172. [CrossRef]

25. Harman, A.M.; MacDonald, A.; Meyer, P.; Ahmat, A. Numbers of neurons in the retinal ganglion cell layer of the rat do not change throughout life. Gerontology 2003, 49, 350-355. [CrossRef]

26. Levkovitch-Verbin, H.; Vander, S.; Makarovsky, D.; Lavinsky, F. Increase in retinal ganglion cells' susceptibility to elevated intraocular pressure and impairment of their endogenous neuroprotective mechanism by age. Mol. Vis. 2013, 19, $2011-2022$. [PubMed]

27. Rodrigo, M.J.; Martinez-Rincon, T.; Subias, M.; Mendez-Martinez, S.; Luna, C.; Pablo, L.E.; Polo, V.; Garcia-Martin, E. Effect of age and sex on neurodevelopment and neurodegeneration in the healthy eye: Longitudinal functional and structural study in the Long-Evans rat. Exp. Eye Res. 2020, 200, 108208. [CrossRef] [PubMed]

28. Cuenca, N.; Fernández-Sánchez, L.; Sauvé, Y.; Segura, F.J.; Martínez-Navarrete, G.; Tamarit, J.M.; Fuentes-Broto, L.; SanchezCano, A.; Pinilla, I. Correlation between SD-OCT, immunocytochemistry and functional findings in an animal model of retinal degeneration. Front. Neuroanat. 2014, 8, 1-20. [CrossRef]

29. Garcia-Martin, E.; Pablo, L.E.; Bambo, M.P.; Alarcia, R.; Polo, V.; Larrosa, J.M.; Vilades, E.; Cameo, B.; Orduna, E.; Ramirez, T.; et al. Comparison of peripapillary choroidal thickness between healthy subjects and patients with Parkinson's disease. PLoS ONE 2017, 12, e0177163. [CrossRef]

30. Garcia-Martin, E.; Pueyo, V.; Martin, J.; Almarcegui, C.; Ara, J.R.; Dolz, I.; Honrubia, F.M.; Fernandez, F.J. Progressive changes in the retinal nerve fiber layer in patients with multiple sclerosis. Eur. J. Ophthalmol. 2010, 20, 167-173. [CrossRef]

31. Ramirez, A.I.; de Hoz, R.; Salobrar-Garcia, E.; Salazar, J.J.; Rojas, B.; Ajoy, D.; López-Cuenca, I.; Rojas, P.; Triviño, A.; Ramírez, J.M. The role of microglia in retinal neurodegeneration: Alzheimer's disease, Parkinson, and glaucoma. Front. Aging Neurosci. 2017, 9 , 1-21. [CrossRef] [PubMed] 
32. Parisi, V. Correlation between morphological and functional retinal impairment in patients affected by ocular hypertension, glaucoma, demyelinating optic neuritis and Alzheimer's disease. Semin. Ophthalmol. 2003, 18, 50-57. [CrossRef]

33. Chouhan, A.K.; Guo, C.; Hsieh, Y.-C.; Ye, H.; Senturk, M.; Zuo, Z.; Li, Y.; Chatterjee, S.; Botas, J.; Jackson, G.R.; et al. Uncoupling neuronal death and dysfunction in Drosophila models of neurodegenerative disease. Acta Neuropathol. Commun. $2016,4,62$. [CrossRef] [PubMed]

34. Moschos, M.M.; Markopoulos, I.; Chatziralli, I.; Rouvas, A.; Papageorgiou, S.G.; Ladas, I.; Vassilopoulos, D. Structural and Functional Impairment of the Retina and Optic Nerve in Alzheimer's Disease. Curr. Alzheimer Res. 2012, 9, 782-788. [CrossRef] [PubMed]

35. Rodrigo, M.J.; Garcia-Herranz, D.; Subias, M.; Martinez-Rincón, T.; Mendez-Martínez, S.; Bravo-Osuna, I.; Carretero, A.; Ruberte, J.; Garcia-Feijoo, J.; Pablo, L.E.; et al. Chronic Glaucoma Using Biodegradable Microspheres to Induce Intraocular Pressure Elevation. Six-Month Follow-Up. Biomedicines 2021, 9, 682. [CrossRef]

36. Morrison, J.C.; Moore, C.G.; Deppmeier, L.M.H.; Gold, B.G.; Meshul, C.K.; Johnson, E.C. A rat model of chronic pressure-induced optic nerve damage. Exp. Eye Res. 1997, 64, 85-96. [CrossRef]

37. Garcia-Herranz, D.; Rodrigo, M.J.; Subias, M.; Martinez-Rincon, T.; Mendez-Martinez, S.; Bravo-Osuna, I.; Bonet, A.; Ruberte, J.; Garcia-Feijoo, J.; Pablo, L.; et al. Novel Use of PLGA Microspheres to Create an Animal Model of Glaucoma with Progressive Neuroretinal Degeneration. Pharmaceutics 2021, 13, 237. [CrossRef]

38. Rodrigo, M.J.; Cardiel, M.J.; Fraile, J.M.; Mendez-Martinez, S.; Martinez-Rincon, T.; Subias, M.; Polo, V.; Ruberte, J.; Ramirez, T.; Vispe, E.; et al. Brimonidine-LAPONITE ${ }^{\circledR}$ intravitreal formulation has an ocular hypotensive and neuroprotective effect throughout 6 months of follow-up in a glaucoma animal model. Biomater. Sci. 2020, 8, 6246-6260. [CrossRef]

39. Ding, C.; Wang, P.; Tian, N. Effect of general anesthetics on IOP in elevated IOP mouse model. Exp. Eye Res. 2011, 92, 512-520. [CrossRef]

40. Nadal-Nicolás, F.M.; Vidal-Sanz, M.; Agudo-Barriuso, M. The aging rat retina: From function to anatomy. Neurobiol. Aging 2018, 61, 146-168. [CrossRef]

41. Liu, X.; Wang, C.H.; Dai, C.; Camesa, A.; Zhang, H.F.; Jiao, S. Effect of contact lens on optical coherence tomography imaging of rodent retina. Curr. Eye Res. 2013, 38, 1235-1240. [CrossRef] [PubMed]

42. Pang, I.H.; Clark, A.F. Inducible rodent models of glaucoma. Prog. Retin. Eye Res. 2020, 75. [CrossRef]

43. Choh, V.; Gurdita, A.; Tan, B.; Prasad, R.C.; Bizheva, K.; Joos, K.M. Short-term moderately elevated intraocular pressure is associated with elevated scotopic electroretinogram responses. Investig. Ophthalmol. Vis. Sci. 2016, 57, 2140-2151. [CrossRef] [PubMed]

44. Tan, B.; Gurdita, A.; Choh, V.; Joos, K.M.; Prasad, R.; Bizheva, K. Morphological and functional changes in the rat retina associated with 2 months of intermittent moderate intraocular pressure elevation. Sci. Rep. 2018, 8, 7727. [CrossRef] [PubMed]

45. Summers Rada, J.A.; Shelton, S.; Norton, T.T. The sclera and myopia. Exp. Eye Res. 2006, 82, 185-200. [CrossRef] [PubMed]

46. Harper, A.R.; Summers, J.A. The Dynamic Sclera: Extracellular Matrix Remodeling in Normal Ocular Growth and Myopia Development. Exp. Eye Res. 2015, 133, 100-111. [CrossRef] [PubMed]

47. Tan, B.; MacLellan, B.; Mason, E.; Bizheva, K. Structural, functional and blood perfusion changes in the rat retina associated with elevated intraocular pressure, measured simultaneously with a combined OCT+ERG system. PLoS ONE 2018, 13, e0193592. [CrossRef]

48. Frankfort, B.J.; Kareem Khan, A.; Tse, D.Y.; Chung, I.; Pang, J.J.; Yang, Z.; Gross, R.L.; Wu, S.M. Elevated intraocular pressure causes inner retinal dysfunction before cell loss in a mouse model of experimental glaucoma. Investig. Ophthalmol. Vis. Sci. 2013, 54, 762-770. [CrossRef] [PubMed]

49. Campbell, I.C.; Hannon, B.G.; Read, A.T.; Sherwood, J.M.; Schwaner, S.A.; Ethier, C.R. Quantification of the efficacy of collagen cross-linking agents to induce stiffening of rat sclera. J. R. Soc. Interface 2017, 14, 20170014. [CrossRef]

50. Cone-Kimball, E.; Nguyen, C.; Oglesby, E.N.; Pease, M.E.; Steinhart, M.R.; Quigley, H.A. Scleral structural alterations associated with chronic experimental intraocular pressure elevation in mice. Mol. Vis. 2013, 19, 2023-2039.

51. Pruett, R.C. Progressive myopia and intraocular pressure: What is the linkage? A literature review. Acta Ophthalmol. Suppl. 1988, 185, 117-127. [CrossRef]

52. Shen, L.; You, Q.S.; Xu, X.; Gao, F.; Zhang, Z.; Li, B.; Jonas, J.B. Scleral and Choroidal Thickness in Secondary High Axial Myopia. Retina 2016, 36, 1579-1585. [CrossRef]

53. Jonas, J.B.; Holbach, L.; Panda-Jonas, S. Histologic differences between primary high myopia and secondary high myopia due to congenital glaucoma. Acta Ophthalmol. 2016, 94, 147-153. [CrossRef]

54. Yassin, S.A. Long-Term Visual Outcomes in Children with Primary Congenital Glaucoma. Eur. J. Ophthalmol. 2017, 27, 705-710. [CrossRef]

55. Liu, B.; McNally, S.; Kilpatrick, J.I.; Jarvis, S.P.; O’Brien, C.J. Aging and ocular tissue stiffness in glaucoma. Surv. Ophthalmol. 2018, 63, 56-74. [CrossRef]

56. Downs, J.C. Optic nerve head biomechanics in aging and disease. Exp. Eye Res. 2015, 133, 19-29. [CrossRef] [PubMed]

57. Nissirios, N.; Chanis, R.; Johnson, E.; Morrison, J.; Cepurna, W.O.; Jia, L.; Mittag, T.; Danias, J. Comparison of anterior segment structures in two rat glaucoma models: An ultrasound biomicroscopic study. Invest. Ophthalmol. Vis. Sci. 2008, 49, 2478-2482. [CrossRef] 
58. Morrison, J.C.; Cepurna, W.O.; Johnson, E.C. Modeling glaucoma in rats by sclerosing aqueous outflow pathways to elevate intraocular pressure. Exp. Eye Res. 2015, 141, 23-32. [CrossRef]

59. Sudhalkar, A.; Bilgic, A.; Vasavada, S.; Kodjikian, L.; Mathis, T.; De Ribot, F.M.; Papakostas, T.; Vasavada, V.; Vasavada, V.; Srivastava, S.; et al. Current intravitreal therapy and ocular hypertension: A review. Indian J. Ophthalmol. 2021, 69, $236-243$. [CrossRef] [PubMed]

60. Hoguet, A.; Chen, P.P.; Junk, A.K.; Mruthyunjaya, P.; Nouri-Mahdavi, K.; Radhakrishnan, S.; Takusagawa, H.L.; Chen, T.C. The Effect of Anti-Vascular Endothelial Growth Factor Agents on Intraocular Pressure and Glaucoma: A Report by the American Academy of Ophthalmology. Ophthalmology 2019, 126, 611-622. [CrossRef] [PubMed]

61. Rebolleda, G.; Puerto, B.; De Juan, V.; Gómez-Mariscal, M.; Muñoz-Negrete, F.J.; Casado, A. Optic nerve head biomechanic and IOP changes before and after the injection of aflibercept for neovascular age-related macular degeneration. Investig. Ophthalmol. Vis. Sci. 2016, 57, 5688-5695. [CrossRef] [PubMed]

62. Guggenheim, J.A.; Creer, R.C.; Qin, X.J. Postnatal refractive development in the Brown Norway rat: Limitations of standard refractive and ocular component dimension measurement techniques. Curr. Eye Res. 2004, 29, 369-376. [CrossRef]

63. Usui, S.; Ikuno, Y.; Uematsu, S.; Morimoto, Y.; Yasuno, Y.; Otori, Y. Changes in axial length and choroidal thickness after intraocular pressure reduction resulting from trabeculectomy. Clin. Ophthalmol. 2013, 7, 1155-1161. [CrossRef] [PubMed]

64. Leo, S.W. Scientific Bureau of World Society of Paediatric Ophthalmology and Strabismus (WSPOS) Current approaches to myopia control. Curr. Opin. Ophthalmol. 2017, 28, 267-275. [CrossRef] [PubMed]

65. Spillmann, L. Stopping the rise of myopia in Asia. Graefe's Arch. Clin. Exp. Ophthalmol. 2020, 258, 943-959. [CrossRef]

66. De Jong, P.T.V.M. Myopia: Its historical contexts. Br. J. Ophthalmol. 2018, 102, 1021-1027. [CrossRef]

67. Kalmann, R.; Mourits, M.P. Prevalence and management of elevated intraocular pressure in patients with Graves' orbitopathy. Br. J. Ophthalmol. 1998, 82, 754-757. [CrossRef]

68. Kim, W.S.; Chun, Y.S.; Cho, B.Y.; Lee, J.K. Biometric and refractive changes after orbital decompression in Korean patients with thyroid-associated orbitopathy. Eye 2016, 30, 400-405. [CrossRef]

69. Huang, A.S.; Li, M.; Yang, D.; Wang, H.; Wang, N.; Weinreb, R.N. Aqueous Angiography in Living Nonhuman Primates Shows Segmental, Pulsatile, and Dynamic Angiographic Aqueous Humor Outflow. Ophthalmology 2017, 124, 793-803. [CrossRef] [PubMed]

70. Huang, A.S.; Francis, B.A.; Weinreb, R.N. Structural and functional imaging of aqueous humour outflow: A review. Clin. Exp. Ophthalmol. 2018, 46, 158-168. [CrossRef] [PubMed]

71. Huang, A.S.; Camp, A.; Xu, B.Y.; Penteado, R.C.; Weinreb, R.N.; Huang, A. Aqueous Angiography: Aqueous Humor Outflow Imaging in Live Human Subjects HHS Public Access. Ophthalmology 2017, 124, 1249-1251. [CrossRef] [PubMed]

72. Lin, K.Y.; Mosaed, S. Ab externo imaging of human episcleral vessels using fiberoptic confocal laser endomicroscopy. J. Ophthalmic Vis. Res. 2019, 14, 275-284. [CrossRef]

73. Khatib, T.Z.; Meyer, P.A.R.; Lusthaus, J.; Manyakin, I.; Mushtaq, Y.; Martin, K.R. Hemoglobin Video Imaging Provides Novel In Vivo High-Resolution Imaging and Quantification of Human Aqueous Outflow in Patients with Glaucoma. Ophthalmol. Glaucoma 2019, 2, 327-335. [CrossRef] [PubMed]

74. Jensen, H. Myopia progression in young school children and intraocular pressure. Doc. Ophthalmol. 1992, 82, 249-255. [CrossRef] [PubMed]

75. Greene, P.R. Mechanical considerations in myopia: Relative effects of accommodation, convergence, intraocular pressure, and the extraocular muscles. Am. J. Optom. Physiol. Opt. 1980, 57, 902-914. [CrossRef] [PubMed]

76. Lee, C.-Y.; Sun, C.-C.; Lin, Y.-F.; Lin, K.-K. Effects of topical atropine on intraocular pressure and myopia progression: A prospective comparative study. BMC Ophthalmol. 2016, 16, 114. [CrossRef]

77. Yam, J.C.; Jiang, Y.; Tang, S.M.; Law, A.K.P.; Chan, J.J.; Wong, E.; Ko, S.T.; Young, A.L.; Tham, C.C.; Chen, L.J.; et al. LowConcentration Atropine for Myopia Progression (LAMP) Study: A Randomized, Double-Blinded, Placebo-Controlled Trial of 0.05\%, 0.025\%, and 0.01\% Atropine Eye Drops in Myopia Control. Ophthalmology 2019, 126, 113-124. [CrossRef]

78. Biswas, S.; Wan, K.H. Review of rodent hypertensive glaucoma models. Acta Ophthalmol. 2019, 97, e331-e340. [CrossRef]

79. Schmidl, D.; Schmetterer, L.; Garhöfer, G.; Popa-Cherecheanu, A. Gender Differences in Ocular Blood Flow. Curr. Eye Res. 2015, 40, 201-212. [CrossRef]

80. Zhou, X.; Xie, J.; Shen, M.; Wang, J.; Jiang, L.; Qu, J.; Lu, F. Biometric measurement of the mouse eye using optical coherence tomography with focal plane advancement. Vis. Res. 2008, 48, 1137-1143. [CrossRef]

81. Jiang, M.; Wu, P.C.; Fini, M.E.; Tsai, C.L.; Itakura, T.; Zhang, X.; Jiao, S. Single-shot dimension measurements of the mouse eye using SD-OCT. Ophthalmic Surg. Lasers Imaging 2012, 43, 252-256. [CrossRef] [PubMed]

82. Chou, T.H.; Kocaoglu, O.P.; Borja, D.; Ruggeri, M.; Uhlhorn, S.R.; Manns, F.; Porciatti, V. Postnatal elongation of eye size in DBA/2J mice compared with C57BL/6J mice: In vivo analysis with whole-eye OCT. Investig. Ophthalmol. Vis. Sci. 2011, 52, 3604-3612. [CrossRef] [PubMed]

83. Hsu, C.-H.; Chen, R.I.; Lin, S.C. Myopia and glaucoma: Sorting out the difference. Curr. Opin. Ophthalmol. 2015, 26, 90-95. [CrossRef] [PubMed]

84. Suwan, Y.; Rettig, S.; Park, S.C.; Tantraworasin, A.; Geyman, L.S.; Effert, K.; Silva, L.; Jarukasetphorn, R.; Ritch, R. Effects of Circumpapillary Retinal Nerve Fiber Layer Segmentation Error Correction on Glaucoma Diagnosis in Myopic Eyes. J. Glaucoma 2018, 27, 1. [CrossRef] 
85. Kansal, V.; Armstrong, J.J.; Pintwala, R.; Hutnik, C. Optical coherence tomography for glaucoma diagnosis: An evidence based meta-analysis. PLoS ONE 2018, 13, e0190621. [CrossRef]

86. Lozano, D.C.; Twa, M.D. Development of a rat schematic eye from in vivo biometry and the correction of lateral magnification in SD-OCT imaging. Investig. Ophthalmol. Vis. Sci. 2013, 54, 6446-6455. [CrossRef] [PubMed]

87. Westall, C.A.; Dhaliwal, H.S.; Panton, C.M.; Sigesmun, D.; Levin, A.V.; Nischal, K.K.; Héon, E. Values of electroretinogram responses according to axial length. Doc. Ophthalmol. 2001, 102, 115-130. [CrossRef]

88. Liu, H.-H.; He, Z.; Nguyen, C.T.O.; Vingrys, A.J.; Bui, B.V. Reversal of functional loss in a rat model of chronic intraocular pressure elevation. Ophthalmic Physiol. Opt. 2017, 37, 71-81. [CrossRef] 